\title{
Study on the Changes of Plant Ecological Communities and Environmental Factors in Cold Cities
}

\author{
Shengju Li ${ }^{1}$, Xue Wang ${ }^{1}$, Yaosheng Zhang ${ }^{1}$, Yuehua Zhang ${ }^{1}$ and Lan $\mathrm{Li}^{2 *}$ \\ ${ }^{1}$ Jiamusi University, Jiamusi City, Heilongjiang Province, 154007, China \\ ${ }^{2}$ School of Data Science and Software Engineering, Wuzhou University, Wuzhou City, Guangxi Province, 543000, China
}

\begin{abstract}
There are certain geographical differences in the design process of green areas along the streets of the cold city. The cold climate brings special geographical features to the city. The snow and ice add new vitality and characteristics to the city, and at the same time public demand new challenges for the excavation and creation of cold garden resources. The definition of standards for cold cities and the contribution of cold cities are movements to cold cities. Green space next to the city streets are systematically defined, and the role and influence of public life generated by the concept of greenbelt are inspected. This paper analyzes the design principles and theoretical basis of the green space design along the street in the cold city. An example is given to analyze the problems and optimization suggestions that should be paid attention to during the design process of the green space next to the city. From the solution of the problematic elements in the greening landscape design along the cold city street, the methods and strategies of the greening landscape design along the cold city street are analyzed from the aspects of plant.
\end{abstract}

\section{Introduction}

The cold city refers to cities that have adversely affected urban life due to long winters and harsh climates. In European and American countries, such cities are called winter cities; in geography studies, people divide the climatic zone according to the latitude of the earth, the area above $60^{\circ} \mathrm{C}$ is the cold zone, and the zone between $40-60^{\circ} \mathrm{C}$ is as the temperate zone [1]. In fact, although the geographic latitude is an important element affecting the cold city, it is not the only factor. Even at the same latitude, the climate type will be completely different. Under the advocacy of the cold city movement, the cold cities are committed to improve their own space environment, improve the quality of life in the cold, and create a living environment in a cold climate [2]. It has enhanced exchanges and cooperation in the fields of social and economic development, urban construction, the energy utilization and environmental protection among international cold cities. It has fully enriched the abundant ice and snow landscape resources that represent the cultural characteristics of the northern cities. It increased visibility of cold cities, with influence throughout the northern temperate zone.

Many countries in the world are located in cold regions, and the number of cold cities in China is also large. The impact of the cold climate on gardens has been neglected for many years, and even the greening construction patterns of other regions with completely different climatic conditions have led to the loss of many cold cities and urban characteristics. Therefore, it is necessary to adopt a series of measures to promote the construction of habitable cold cities, offset the fear of cold environment, enhance the environmental attractiveness of cold cities, and enable the cold cities to follow the path of sustainable development [3]. Solving this problem is a challenge for cold garden designers. Green areas along the streets of the cold city are an important stage for people's social life. They directly affect the daily life of the public and represent the image of the cold city. The living conditions of urban residents are gradually improving, and the per capita housing area is also increasing year by year. Gradually, people are no longer satisfied with the improvement of the internal conditions of the housing. In their spare time, they prefer to communicate and contact with the outside world, and they are willing to feel the fresh air in their leisure time. Thereby further improving the quality of life of urban residents. Strengthening the construction of green space next to the streets of cold cities, with relatively little investment and quick results, can increase the area of green areas and alleviate the uneven distribution of green areas.

Through the construction of green spaces along the street, it is also possible to properly isolate and protect historical and cultural blocks and cultural security land, prevent invasive construction from infiltrating into the inner city. The green space along the street has the function of enhancing ecological functions. Within a certain concentration range, the plants in the green space along the street have certain absorption and purification effects on harmful gases, and also have obvious blocking, filtering and adsorption effects on soot and dust. The

*Corresponding author's e-mail: 1ljmsu@163.com 
underground roots of plants in the green spaces along the street can absorb a large amount of harmful substances and have the ability to purify the soil. In addition, the green spaces along the street also have ecological functions such as improving local microclimates on urban streets and reducing noise pollution. With the acceleration of urbanization in China in recent years, the construction of all aspects of the city is in full swing.

Although the green space next to the city street is not large, it can be obtained by providing the most basic green space and activities for the surrounding community residents. Great development, this change is also complementary to the improvement of people's living standards. Strengthening the construction of green space along the street is in line with the scientific law of green space construction. It is the direction of future green space construction and development. In the cold city, the field of green space is deeply studied. Gradually withered, however from the perspective of protecting the environment and improving the ecology, the environmental landscape is rationally configured and landscaped, and considering the diversified functions of the green space, it can bring the desired natural environment and tranquil atmosphere.

\section{Experimental design and materials}

\subsection{Lack of cold urban landscape features}

The largest climatic characteristics of cold cities are mainly due to seasonal differences, long sunshine hours in summer, short winter sunshine hours, long winters, cold, snowfall, etc. Therefore, the pursuit of satisfying human physiology and behaviour in the design of the outer space of cold cities. The psychological aspects should be an important starting point for the thermal comfort of the environment. It is mainly affected by the climatic factors in the following aspects of winter: temperature and humidity are the main factors affecting human thermal comfort. The starting point and design strategy for urban design in severe cold regions is to focus on insulation in winter and create a suitable environment to meet people's thermal comfort requirements, which is significantly different from the landscape design in summer and hot regions [4].

The seasonal wind was described by two variables: wind direction and wind speed. In winter, the prevailing winds of cold cities are mainly northward, and the wind speed is large. The impact of wind on urban design is mainly reflected in how to create a comfortable wind environment through reasonable street orientation, building layout and other corresponding design methods. In cold cities, it is necessary to shield the prevailing winter winds for heat preservation, and to design the "wind tunnel" to introduce the summer wind into the city to achieve natural ventilation. Winters in North America and Asia are mainly snowfall in winter, and the winters in Nordic cities are more rainy and snowy. Frequent snowfall brings problems with snow cleaning and utilization to cold cities, especially traffic problems. Effective urban space organizations can facilitate the cleanup and use of snow. According to the climatic characteristics of the cold city, the design of the external public space of the cold city should take into account the summer heat of the cold weather and the seasonality of the cold winter.

$$
\begin{aligned}
& \text { (1) Species diversity index }: H^{\prime}=-\sum_{i=1}^{s} P_{i} \ln P_{i} \\
& \text { (2) Species uniformity index : } E=H / \ln S \\
& \text { (3) Species dominance index :C}=\sum_{i=1}^{s} N_{i}\left(N_{i}-1\right) / N(N-1) \\
& \text { (4) Species richness index : } D_{m g}=L(S-1) / \ln N
\end{aligned}
$$

\subsection{Different protective measures are formulated in different seasons}

Taking winter as the focus, from protecting and improving the urban ecological environment, reducing the loss of winter heat energy, and reducing the discomfort caused by outdoor cold, snow and wind on the human body and psychology as its manpower point. However, its design philosophy is not to create the same winter living environment as in summer, but to play the characteristics of the northern city, making the winter living environment safer, more comfortable and enjoyable (in Tab.1).

Table 1. Shengshan forest community substitution $\beta$ multi-repetitive change

\begin{tabular}{lllllll}
\hline & & BIRCH & LARCH & WEED & OAKR & RED-PINE \\
\hline $\mathrm{C}_{\mathrm{J}}$ & POPLAR & 0.487 & 0.455 & 0.485 & 0.482 & 0.443 \\
& BIRCH & - & 0.447 & 0.376 & 0.407 & 0.435 \\
& LARCH & - & - & 0.426 & 0.454 & 0.382 \\
& WEED & - & - & - & 0.472 & 0.309 \\
& OAKR & - & - & - & - & 0.298 \\
$\mathrm{C}_{\mathrm{S}}$ & POPLAR & 0.655 & 0.625 & 0.653 & 0.650 & 0.614 \\
& BIRCH & - & 0.618 & 0.547 & 0.579 & 0.606 \\
& LARCH & - & - & 0.597 & 0.624 & 0.553
\end{tabular}




\begin{tabular}{|c|c|c|c|c|c|c|}
\hline \multirow{7}{*}{$\beta_{\mathrm{C}}$} & WEED & - & - & - & 0.641 & 0.472 \\
\hline & OAKR & - & - & - & - & 0.459 \\
\hline & POPLAR & 29.500 & 33.000 & 26.000 & 28.500 & 34.000 \\
\hline & BIRCH & - & 31.500 & 31.500 & 32.000 & 32.500 \\
\hline & LARCH & - & - & 29.000 & 29.500 & 38.000 \\
\hline & WEED & - & - & - & 23.500 & 38.000 \\
\hline & OAKR & - & - & - & - & 42.500 \\
\hline
\end{tabular}

Evergreen plants can block the cold wind in winter. Even deciduous plants can reduce the wind speed in winter, and the beautiful image of the branches after snow can add all the fun to the winter, and it is more human than the bare hard landscape. Summer is a good time for plants to work. The ecological benefits of plants can reduce the ambient temperature, and broad-leaved plants can form rich shades. People can enjoy the coolness and conversation under the trees, providing a comfortable place for residents' outdoor activities. The hard landscape reflects solar radiation during the summer, making the outdoor environment even more difficult. The soft landscape is long-lasting, and the hard landscape is quick. In contrast, the plant landscape can only play its due role in a few years. It takes a while to reach the best viewing period, because some external factors may affect it.

\subsection{Lack of cold urban landscape features}

In the north-eastern part of China, some traditional buildings in the cold city, residents in the long-term life practice summed up a set of architectural organization that adapts to the climate characteristics of the cold city, it is thick and heavy, and the color is gorgeous. The rough and heavy weight reflects both the unrestrained character of the northerners and the resistance to the wind and sand. The color is gorgeous because the winter city is full of depression in the winter, and the gorgeous colors can add some bright colors to the gray winter. At present, many designers do not extract elements from these existing excellent traditions, but blindly imitate the lake and rockery in the south and even the gray tones, making the cold winter chill more concentrated. There are four distinct seasons in the cold city. The deciduous plants have four expressions: spring flowers, summer leaves, autumn colors, and winter branches. There are ice lamps and snow sculptures in winter. These are the special features that are not found in the warm regions of the south. And now there are fake artificial things in the green areas along the streets of the cold city, such as plastic fake flowers, fake grass, imitation tropical plants, animals, etc., as well as southern plants and large lawns that are not suitable for the cold climate. The cold urban green space has lost its own landscape characteristics.

\section{3 results and analysis}

\subsection{Low utilization rate of outdoor activities}

In some of the green areas that have been built in the cold city streets, there is a lack of recreational venues, or few people use them in existing venues. The cold winter city is cold in winter, and the dominant wind direction is northwest. If the activity site lacks effective blocking of the raging winter cold wind, and even the layout between the buildings is improper, under the squeezing effect of the building on the wind, the wind speed of the activity site is strengthened. At the same time, if the building in the sunny direction of the event site is too strong and the activity site is in the shadow of the building, these factors will lead to low utilization of the outdoor event site in winter [5]. The cold winter cities in the north are not only cold in winter but also hot in summer. Outdoor activities need to be sheltered from wind and winter in winter, and ventilation and shading in summer. Therefore, outdoor activities in cold urban residential areas require shaded facilities during the summer. However, the lack of these facilities in the environment outside the residential area of the cold city and the lack of distinctive activities have further reduced the attractiveness of outdoor activities in the residential areas of the cold cities.

\subsection{Design of plant elements in the green space in the cold city}

In the design of cold gardens, the species of cold plants are mainly deciduous trees and evergreen conifers. Planting the effect of "architectural" in the process of plant configuration is not just a decoration. In the landscape environment, the function of the plant is to form an outdoor space, to block objects that are unfavorable to the landscape, to protect the slope, and to play a guiding role in the landscape. In the green space next to the cold city street, the important role of plant configuration is to adjust the light and wind speed, so that the summer shade and ventilation, winter sun and wind, thus creating a pleasant microclimate suitable for cold urban residential areas. In the cold winter, the northwest wind is more likely to be scattered in the winter, and the evergreen trees should be placed in the northwest direction in the green space.

\section{Conclusions}

The landscape design of the street-side green space in the cold city is very complicated, and it is necessary to continuously supplement the sustainable process of research, and continuously penetrate the regional and urban characteristics of the cold city throughout the design process. There are different cultures and regions. The green space along the street is an organic part of the green space system [6]. Its design is also constantly developing with the changes of the times. With the development of the city and the continuous improvement of people's living standards, public demand for urban environment and quality are also increasing [7].

As one of the main windows reflecting the style of the cold city, the green space along the street of the cold 
city will pay more attention to the increase of quantity and area from the past, and gradually turn to the comprehensive consideration of the higher requirements for the quality of landscape design. In response to these situations, the author's research on the subject will become more and more abundant and systematic with the continuous collection, collation and analysis of a large amount of data and field investigation and analysis in other cold cities [8].

The excavation and development and utilization of garden environmental resources, the landscape design reflecting the characteristics of the cold land and the specific landscape of the special section adhere to the design process. Therefore, the state of treating the different seasons of the cold city is not enough, so that the garden can provide seasonal use, and the winter can also be utilized, thereby enriching the landscape design of the green area along the cold city street. Taking the green space next to the street in the cold city as the carrier, while shaping the style characteristics of the green landscape near the cold city street, we can make full use of the characteristics of the green space on the street to be flexible and changeable, and boldly create a city landscape with urban cultural themes [9]. In the process of designing in the future, more attention will be paid to the detailed processing of landscape design techniques, from the better understanding of the landscape details and the improvement of the quality of the cold urban landscape environment, and the influence of the cold city in the world.

\section{Acknowledgement}

Heilongjiang Provincial Department of Education Basic Research Project (2018-KYYWF-0936); The Core Talent of Jiamusi University (JMSURCGG2016-001); The China Scientific and technological innovation projects in Heilongjiang Province, college students: 201910222010.

\section{References}

1. Pressman N E P. (1996) Sustainable winter cities: Future directions for planning, policy and design. J. Sci. Atmospheric environment, 30: 521-529.

2. Matus V. (1988) Cold-climate planning and environmental design. J. Sci. Design for Northern Climates. 1:25-30.

3. Newman P, Kenworthy J. (2001) Transportation energy in global cities: sustainable transportation comes in from the cold. J. Sci. Natural resources forum. Oxford, UK: Blackwell Publishing Ltd, 25: 91-107.

4. Tucker P, Gilliland J. (2007) The effect of season and weather on physical activity: a systematic review. J. Sci. Public health, 121: 909-920.

5. McMichael A J, Woodruff R E, Hales S. (2006) Climate change and human health: present and future risks. J. Sci. The Lancet, 367: 859-869.

6. Bolund P, Hunhammar S. (1999) Ecosystem services in urban areas. J. Sci. Ecological economics, 29 293-301.

7. Petersen P E. (2003) The World Oral Health Report 2003: continuous improvement of oral health in the 21 st century-the approach of the WHO Global Oral Health Programme. J. Sci. Community Dentistry and oral epidemiology, 31: 3-24.

8. Krewski D, Burnett R, Goldberg M, et al. (2003) Overview of the reanalysis of the Harvard six cities study and American Cancer Society study of particulate air pollution and mortality. J. Sci. Journal of Toxicology and Environmental Health Part A, 66: 1507-1552.

9. Jim C Y. (2013) Sustainable urban greening strategies for compact cities in developing and developed economies. J. Sci. Urban Ecosystems, 16: 741-761. 